\title{
"Green Ocean Treasure Hunting" Guided by Policy Support in a Transitional Economy
}

\author{
Baoshan Ge ${ }^{1}$, Fan Sheng ${ }^{1}$, Yang Gao ${ }^{2, *}$, Sang-Bing Tsai ${ }^{3,4, *(1)}$ and Xiaomin Du ${ }^{5}$ \\ 1 School of Management, Jilin University, Changchun 130022, China; gebaoshan@vip.163.com (B.G.); \\ shengfan16@mails.jlu.edu.cn (F.S.) \\ 2 School of Business, Dalian University of Technology, Panjin 124221, China \\ 3 Zhongshan Institute, University of Electronic Science and Technology, Zhongshan 528400, China \\ 4 Business and Law School, Foshan University, Foshan 528000, China \\ 5 Department of Economic Management, Yingkou Institute of Technology, Yingkou 115014, China; \\ dxm0304058@163.com \\ * Correspondence: gzm@dlut.edu.cn (Y.G.); sangbing@hotmail.com (S.-B.T.); Tel.: +86-760-8832-8103 (S.-B.T.)
}

Received: 9 January 2018; Accepted: 7 February 2018; Published: 8 February 2018

\begin{abstract}
For countries in the process of economic transition, improvement of industrialization is no longer the sole goal of their economic development. While upgrading the level of industrial development, these countries also gradually attach importance to resource utilization efficiency and environmental protection, which is why green entrepreneurship has become increasingly popular in recent years. With the intensification of policy guidance, a new "sea area" named green entrepreneurship ushers in more and more "treasure hunters" exploring "the treasure" therein. Based on this, this paper constructs the model of "Green Ocean Treasure Hunting" for green entrepreneurial enterprises to analyze the role played by their government's relevant policies and puts forward the research proposition of this article based on the relevant literature. On this basis, this paper chooses and analyzes a medium-sized, high-tech enterprise in China which follows a certain typical green entrepreneurial process as evidence of the propositions we have put forward.
\end{abstract}

Keywords: green entrepreneurship; policy support; innovative search; biomass energy; green ocean; sustainability

\section{Introduction}

In recent years, with the continuous improvement of industrialization, people have been plagued by increasing environmental pollution and a lack of resources, in addition to more convenient living. This has caused countries to pay more attention to environmental protection and sustainable development. The same is true in China. After extensive catching-up economically and ensuring that it met the livelihood needs of people throughout the country, it began to gradually increase its protection of the environment and resources and turned to a sustainable economic growth model. Both the "Scientific Outlook on Development" proposed by the Third Plenary Session of the 16th CPC Central Committee and the "Ecological Civilization Building" proposed by the 18th CPC Congress directly address the practical problems of resource constraints and environmental pollution, in order to lead China's development in a green and harmonious direction. In order to achieve this goal, the Chinese government has formulated many policies to standardize and guide the development of domestic industries, such as the "Law of the People's Republic of China on Promoting Circular Economy", the "Decision on Accelerating the Cultivation and Development of Strategic Emerging Industries", the "National Environmental Protection Standard for the Thirteenth Five-year Development Plan" and so on. Under the support and guidance of a series of relevant policies, some entrepreneurs and entrepreneurial enterprises have begun to choose a more environmentally friendly, economical and 
ecological means of development, that is, to embark on green entrepreneurship. However, this road is not smooth, but full of challenges.

The target of this paper is to research the phenomenon of green entrepreneurship, analyze the challenges that green entrepreneurship brings to entrepreneurs and entrepreneurial enterprises, and the role of policy support in promoting and supporting green entrepreneurship. On this basis, it is easier to understand the practice of green entrepreneurship through the metaphor of a treasure hunt in the Green Ocean, and thus to clarify why and how entrepreneurs and entrepreneurial enterprises try to start green businesses and face challenges. After theoretical analysis, we then continue by analyzing a high-tech enterprise in China that undertakes green entrepreneurship, in order to pursue a deeper theoretical and practical contribution.

\section{Theoretical Basis}

\subsection{Green Entrepreneurship}

When it comes to green entrepreneurship, one cannot ignore green technologies, which are products, services or processes that deliver value with less resources or pollution than current standards [1,2]. Green entrepreneurial enterprises pursue the goal of using green technologies to protect the environment and resource enterprises. Many scholars had conducted relevant research around the topic of green entrepreneurship. Scholars have given their own definitions to it and also introduced different terms such as sustainable entrepreneurship, environmental entrepreneurship, eco-entrepreneurship and green entrepreneurship in order to describe it. In this paper, we choose the term "green entrepreneurship" to indicate this phenomenon. The following is a list of some definitions of these scholars, as shown in Table 1.

Table 1. Definitions of green entrepreneurship.

\begin{tabular}{|c|c|}
\hline Author & Definition \\
\hline Dean and Mcmullen [3] & $\begin{array}{l}\text { Green entrepreneurship is the result of individuals in the market } \\
\text { who wish to stop activities that led to environmental damage } \\
\text { and are willing to pay for it. Green entrepreneurship is the } \\
\text { process of identifying, assessing and using } \\
\text { environmental-related opportunities emerging from market } \\
\text { failures that are detrimental to sustainability. }\end{array}$ \\
\hline Kai and Wüstenhagen [4] & $\begin{array}{l}\text { Identifying and exploiting opportunities through the emergence } \\
\text { of market imbalances, this therefore shifts sectors towards being } \\
\text { more socially and environmentally sustainable. }\end{array}$ \\
\hline Shepherd and Patzelt [5] & $\begin{array}{l}\text { Green entrepreneurship is the pursuit of opportunities for the } \\
\text { future products, processes and services, which focuses on the } \\
\text { protection of nature, life and society. }\end{array}$ \\
\hline Kate and Eva [6] & $\begin{array}{l}\text { Green entrepreneurship is bringing new products, technologies } \\
\text { and services to the market to try and guide the industry and } \\
\text { consumer in a way that is environmentally and socially } \\
\text { beneficial in this process. }\end{array}$ \\
\hline Silajdžić, Kurtagić and Vučijak [7] & $\begin{array}{l}\text { Green entrepreneurship is the entrepreneurship and the sale of } \\
\text { green products and services based on the principle of sustainable } \\
\text { development of strong potential green values. }\end{array}$ \\
\hline Corbett and Montgomery [8] & $\begin{array}{l}\text { Green entrepreneurship is the response of individuals or } \\
\text { organizations to address issues of uncertainty and resource } \\
\text { allocation through novel and unique ideas and perspectives and } \\
\text { to improve the environment by identifying, discovering, } \\
\text { developing, innovating and exploiting opportunities. }\end{array}$ \\
\hline
\end{tabular}


It can be seen that, although a recognized definition has not yet been made for green entrepreneurship, there are still commonalities that exist. First of all, green entrepreneurship is a way to achieve environmental goals through entrepreneurship, in the process of which the identification, exploitation and other processes of opportunities were emphasized. Secondly, green entrepreneurship has emerged due to market imbalances, resource allocation imbalances and other stimulating conditions, with ensuring environment protection and sustainable development being one of its main purposes. Thirdly, green entrepreneurship also needs innovation, foresight and risk-taking to develop and promote new products, technologies and services. Based on this, the green entrepreneurship in this paper mainly considers the research, development, improvement and promotion of products, technologies and services by organizations or individuals exploiting entrepreneurial opportunities for environmental protection and sustainable development.

\subsection{Green Entrepreneurship and Policy Support}

Policy support has an impact on entrepreneurship. Fonseca et al. have shown that the entrepreneurial costs of entrepreneurs are influenced by relevant policies [9]. Higher entrepreneurial costs will inhibit entrepreneurs' willingness to start their business and thus can reduce the speed with which new businesses in a country are established. Ge et al. [10] believe that policy support, such as the incentives, innovative protection and government programs, can play a role in promoting the development of entrepreneurial activities and lowering the threshold for market access . Furthermore, for green entrepreneurship, Pinkse and Groot argue that in the face of market barriers such as imperfect information, monopolies and price mechanism imbalances, green entrepreneurial enterprises tend to engage in political activities to gain government support for smooth entry into their target industry [11]. However, research by Kai and Wüstenhagen [4] examines government internalization of external costs through taxation and other policy measures, and shows that policy support plays an important role in promoting the commercialization of sustainable innovation outcomes. Therefore, to encourage sustainable entrepreneurship by enterprises, more should be learnt about policy. Moreover, the development of green entrepreneurship is a complex process that requires the comprehensive utilization of technologies, policies, markets and more, and the government's greatest responsibility is to provide entrepreneurs with the appropriate and necessary support to address uncertainties and risks, so as to help businesses to navigate barriers more smoothly [7]. Therefore, in this study, the analysis of the role of policy support in green entrepreneurship is emphasized, which also matches the important role of government in the transitional economy.

\subsection{Innovative Research}

Many scholars have conducted research on innovative research. For example, Katila and Ahuja argue that innovative research is an attempt by enterprises to solve problems in a fuzzy world and that this process may involve the creation and consolidation of technologies [12]. Sofka and Grimpe define innovative research as the research and integration of external knowledge across boundaries by companies to help them innovate successfully and enhance the novelty of innovation [13]. From the perspective of innovative research, this behavior can be further decomposed. For example, according to the target of research, innovative research can be divided into market knowledge research about customer preferences and technical knowledge research for the design, production and technology, etc. of products and services [14]. It can also be divided by the direction of the innovative research, such as the breadth of research for heterogeneous knowledge beyond existing knowledge and the depth of research for knowledge of the enterprise's own knowledge reserve [12].

\section{Model Building}

In the Blue Ocean Strategy, Kim and Mauborgne divided the market into the blue oceans (unknown market spaces), which consist of non-existent industries and the red oceans (known as market spaces), which consist of existing industries [15]. This metaphor gave us inspiration. Green entrepreneurship is about novel entrepreneurship that is environmentally and socially friendly, 
which makes green entrepreneurship supported by the government and the general public as people like to live in a beautiful environment. Such support is often reflected in environmental factors, such as policies and cultures. Therefore, we compare the market for green entrepreneurial enterprises to a "Green Ocean", where external environmental factors such as policies play an important role in this green ocean. Guided by the external environment, green entrepreneurial enterprises in this ocean exploit the opportunities and resources it identified and accessed to carry out the corresponding innovation activities to explore the "treasure of the sea". In other words, researching and developing, or improving the production process for, more environmentally friendly products and services. This kind of "Green Ocean", on the one hand, possesses characteristics of the blue ocean, that is, the innovation results from the country's demand for sustainable development and people's demand for a green and healthy ecological environment. Therefore, green entrepreneurial enterprises offer unique competitive advantages. On the other hand, "Green Ocean" also possesses some characteristics of the red ocean. That is, the fruits of many green entrepreneurial enterprises are just innovations in manufacturing processes, but not much different from other non-green products in terms of the function and performance of the product itself, both of which have strong alternatives. These companies will still face fierce competition in the market with a large number of alternative products. In this case, what troubles them is how their innovative costs can be remedied.

At present, in order to develop, enterprises not only need to seize and use opportunities to create value, but also to take into account any social benefits, combined with considering the relevant laws and regulations. This makes companies' development strategies place more emphasis on sustainability in addition to their day-to-day operations, namely in addition to meeting economic, technical and customer needs. This quest seeks to achieve sustainable product manufacturing with cheaper and more abundant ingredients [16]. For enterprises, the pursuit of more sustainable development is based on their recognition of the scarcity of natural resources and the need for businesses to take responsibility for the use of social resources. Thus, in the pursuit of green development, enterprises will use their resources and capabilities for business activities in a more sustainable manner [17]. Many companies choose green entrepreneurship and make innovations in a sustainable way under the influence of multiple factors such as politics, society and themselves. These companies often need to keep an eye on changes in market demand and rapidly respond to them [18]. Therefore, it is necessary to explore the innovation of enterprises in order to achieve green and sustainable development in the research of green entrepreneurship. Thus, in this paper, we study the green entrepreneurship problem in terms of policy support in the transition economy and build a research model, mainly considering the role of policy support, the technological complexity that enterprises face in their innovative research and the innovative outcomes they have achieved.

Block found that policy support has played a significant role in the technological innovation of enterprises [19]. The government helps enterprises to obtain resources through funding and support for the commercialization of new technologies in order to help enterprises to carry out technological innovation smoothly. Sofka and Grimpe argue that innovative research is the process by which companies cross boundaries to gain external knowledge resources and use them for business innovation [13]. For researchers and developers, a high level of technological complexity puts them in a dilemma, making them spend more time exploring the various components and their interactions in complex technologies, as opposed to lower technological complexity which reduces the need for tedious explorations $[20,21]$. Therefore, we can start from a similar point of view when we study green entrepreneurship. This paper mainly focuses on analysis of the impact of policy support and the enterprise's innovative research on their resource acquisition, and also the technological complexity faced by them in the innovation process, and then analyzes how the above factors affect the innovative outcomes of green entrepreneurial enterprises (as shown in Figure 1). It should be noted that the resources mentioned here include not only the operating resources of enterprises, but also the knowledge resources. 
To show the process more vividly, we analogize that the process of green entrepreneurship, and the individuals and organizations that start a green business, are like "treasure hunters" in this "Green Ocean", where they explore the "treasure department "under policy support (potential business opportunities). Green entrepreneurship uses its own unremitting innovation as a driving force to find and tap into the "treasure" and build the "Green Ocean Treasure Hunting" model (as shown in Figure 2). Based on the metaphor of green ocean and referring the mechanics of gravity, buoyancy and other principles, we show the way in which entrepreneurial enterprises are supported and hindered during this process. This is in order to show green entrepreneurship more intuitively through the process by which enterprises continuously explore and pursue innovative achievements under the influence of various forces.

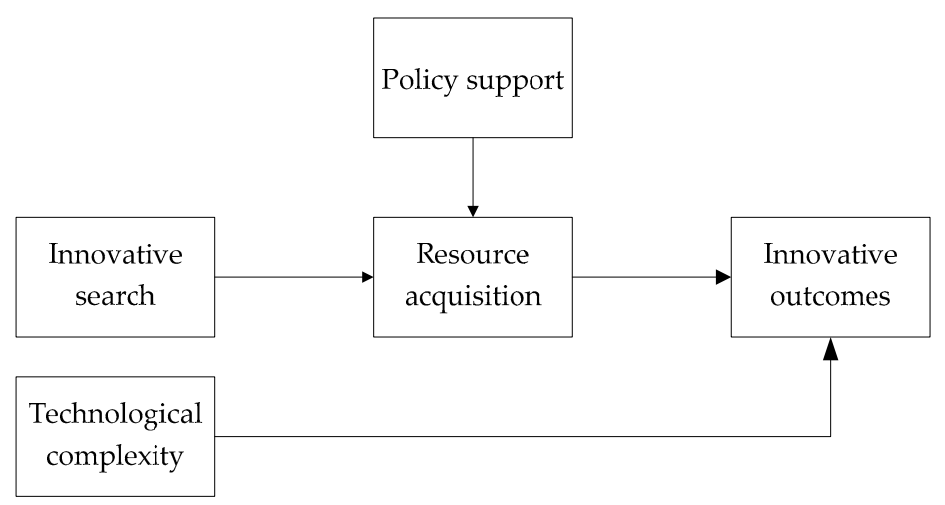

Figure 1. Research framework of "Green Ocean Treasure Hunting".

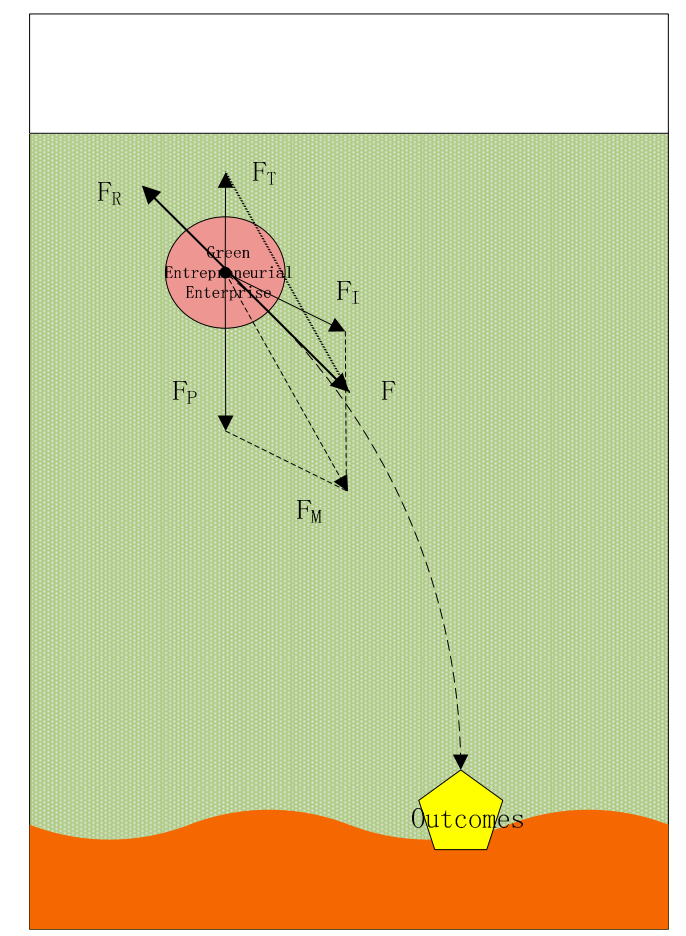

Figure 2. "Green Ocean Treasure Hunting" model.

If an entrepreneurial enterprise is likened to a uniform, solid sphere of water and related policies as external environmental factors are viewed as a field, then the role of policy support, $\mathrm{F}_{\mathrm{P}}$, for entrepreneurial enterprises can be compared to the gravitational force, $G$, that the sphere is subjected to. Similarly, for green entrepreneurial enterprises, policy support, like gravity, is a downward force. 
In other words, the force of policy supports in promoting enterprises' innovation and brings them closer to the green product and technology development. The supportive role of policy support for green entrepreneurship is related to the intensity of policy support, that is, the intensity of the incentives, subsidies and tax relief provided by the relevant policies. From the perspective of R\&D subsidies, research and development costs plus deductions, scientific research awards and so on, the intensity of impact on the entrepreneurial enterprise is related to its input and achievement in green entrepreneurship. Based on this, we use $\mathrm{F}_{\mathrm{P}}$ in Figure 2 to express the force of policy support received by green entrepreneurial enterprises.

Green entrepreneurial enterprises need to innovate and improve their products, services, technologies and processes, etc. for environmental protection and resource conservation. This requires entrepreneurial enterprises to take the initiative to make innovative research to get closer to their "destination". In this process, enterprises should make efforts on technical aspects to enhance their understanding and utilization of their knowledge (technical knowledge research). On the other hand, while the entrepreneurial activity of an entrepreneurial enterprise is purposeful, it still requires the enterprise to conduct research on its own initiative to help them explore the true location (market knowledge research) of their targeted R\&D outcomes so as to avoid their innovative behavior falling astray and resulting in financial losses. Therefore, in this paper's model, the innovative research of green entrepreneurial enterprises is the force, $\mathrm{F}_{\mathrm{I}}$, which is roughly oriented towards the "treasure" provided by the enterprises themselves, which have a horizontal and vertical component. According to the principle of resultant force in physics, the force is a vector and the vector sum of multiple forces acting on the same object is the resultant force of these forces. According to the parallelogram law, the motivation, $\mathrm{F}_{\mathrm{M}}$, that promotes entrepreneurial enterprises to be successful in innovations is the resultant force of $\mathrm{F}_{\mathrm{P}}$ and $\mathrm{F}_{\mathrm{I}}$.

Most of the green entrepreneurial enterprises are innovative new ventures or small and medium-sized businesses (SMEs) that are able to respond more positively to the demand for green products than large ones in almost any market segment, but they also often face higher technical uncertainty [2,22]. For green entrepreneurial enterprises, they need to overcome the technological complexity in pursuing innovation achievements, such as green products and services. In this paper's model, this process is manifested in the entrepreneurial enterprises' efforts to overcome the buoyancy of "green sea" and move to the "seabed". In physics, the buoyancy that an object receives in a liquid can be expressed as $\mathrm{F}_{\text {float }}$. When comparing the technological complexity faced by green enterprises to achieve buoyancy, and considering that the technological complexity of their corresponding fields is higher, the obstacles for successful innovation will therefore be larger. When a kind of technology required by various countries faces greater obstacles, these countries tend to make efforts to increase the attractiveness to provide such technologies [23]. This also reflects the difficulties and technological complexity required for innovation. Taking these aspects into consideration, the technological complexity faced by green entrepreneurial enterprises can be expressed by $\mathrm{F}_{\mathrm{T}}$ in Figure 2 .

On this basis, according to the parallelogram law, we can add up the impetus of the enterprise and the buoyancy caused by technological complexity, consequently then, the resultant force, $\mathrm{F}$, is the force that influences the actual trajectory of green entrepreneurship of enterprises. In addition, in the course of their movement in the "Green Ocean", enterprises are constantly hindered by resistance which is contrary to their direction of movement. For ordinary moving objects, this resistance can be simply expressed as f. For green entrepreneurial enterprises, considering that various resources are essential to their entrepreneurial processes and the cornerstones of their innovation, the difficulty of acquiring knowledge and other kinds of resources can be a further obstacle to them. This obstacle relates to the enterprise's current level of requirement on these resources and also the influence of organizational structure, personnel composition, relevant domain knowledge and resource availability on the process of acquiring these resources needed for entrepreneurship. The result of the combination of these two aspects is the difficulty faced by enterprises in acquiring knowledge and other resources, which can be expressed by $F_{R}$ in Figure 2. 


\section{Mechanism Analysis on Green Entrepreneurship Guided by Policy Support}

In a study of wind power industry enterprises in 12 countries, such as China and Brazil, Lewis and Wiser found that direct and indirect policy support, such as fiscal incentives, tax credits, government purchases and feed-in tariffs, can help promote the development of the wind energy industry [23]. This process happens with the emergence of a large number of new entrants, products and technologies in the industry. Stigson et al. studied the energy and climate policies of Sweden, and considered that enterprises are paying increasing attention to corresponding policies when making investment decisions for related industries [24]. Since the government cannot directly control the emissions of enterprises, but can only adopt policy measures to regulate and motivate enterprises to reduce their emissions, investment direction should be guided by policy measures.

In the light of the externality theory, the production process of enterprises in real life tends to be accompanied by certain external influences, in other words the private benefits brought by their production activities are less than the social benefits (positive externality), or the private costs are less than the social costs (negative externality). Moreover, unlike the hypothetical enterprises in neoclassical economics, which can perfectly use resources, actual enterprises can hardly achieve full utilization of resources in the production process. As Cohen and Winn have written, market failures such as externality and inefficiency can provide enterprises with opportunities for green entrepreneurship, and these opportunities are abundant in reality [25]. Therefore, for the government, in order to deal with the problem of environmental pollution and lack of resources, it is necessary to guide enterprises through policies to green entrepreneurship, so that enterprises can produce positive externalities or reduce negative externalities and increase the efficiency of their resource utilization. Entrepreneurial enterprises decide whether to take advantage of these opportunities based on whether these business opportunities are profitable [26], so whether or not enterprises are willing to adopt green entrepreneurship and where it is going are also affected by policy. That is to say, enterprises will measure the costs and benefits that may be brought by green entrepreneurship as an important reference point for decision-making, while direct or indirect policy support, such as tax incentives and subsidies, can help enterprises reduce costs or generate additional revenue. Therefore, when the government formulates or adjusts corresponding policies, the organization or individual will decide whether to take the opportunity to conduct green entrepreneurship based on its measurement of the risks and benefits [27]. Policy support at this time is equivalent to a "Green Ocean Treasure Map" provided by the government. The "treasure hunters" who were attracted will explore where the "Treasure" is located according to the "Treasure Map". At the same time, the government also holds a role in using policy support to guide the development of green entrepreneurship. Taking the new energy industry as an example, as shown in Figure 3, since the promulgation and implementation of the "National long-term science and technology development plan" and "Renewable Energy Law" in 2006, the number of new domestic energy enterprises registered in China has experienced rapid growth, with new energy enterprises established after 2006 accounting for nearly $90 \%$ of the total number of new energy enterprises. Therefore, this paper puts forward Proposition 1.

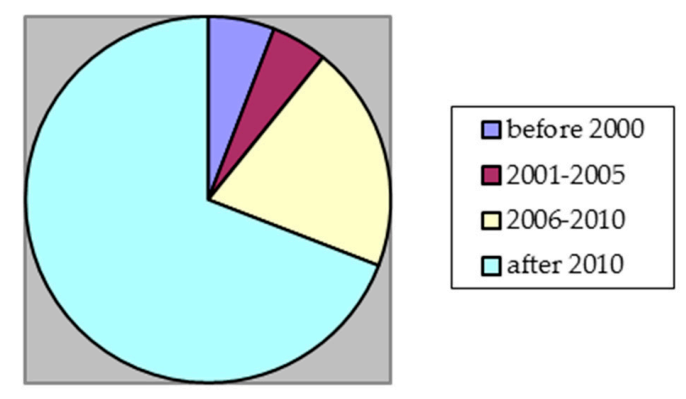

Figure 3. The time of establishment of China's newly registered energy enterprises. (Source: Tencent Finance, Jusfoun Bigdata) [28]. 
Proposition 1. Policy support can guide the direction of green entrepreneurship.

A good institutional environment can promote entrepreneurship [29]. Based on the Porter [30] Hypothesis, Ramanathan et al. [31] suggest that flexible environmental regulations that encourage enterprises to innovate can drive enterprises to dynamic innovation and have a positive impact on their performance and sustainability. For green entrepreneurship, policy support can also provide momentum. Specifically, due to the environmental and social demands for green entrepreneurship, policy support such as tax credits, $R \& D$ subsidies and achievement rewards formulated and promulgated by the government can directly or indirectly provide enterprises with resources, enhance the competitiveness of their products (such as encouraging green consumption, enhance environmental standards, etc.) or expand the market for enterprises (such as government procurement, introduction of planning for promotion, etc.), thus reducing the enterprises' cost of design, research and development, production and transaction. Thus, for green entrepreneurial enterprises, these policy supports boost their entrepreneurial activities $\left(\mathrm{F}_{\mathrm{P}}\right)$, which can, on the one hand, make enterprises more successful at overcoming obstacles to accessing knowledge and other resources $\left(\mathrm{F}_{\mathrm{R}}\right)$, as well as understanding technological complexity $\left(\mathrm{F}_{\mathrm{T}}\right)$ in the process of $\mathrm{R} \& \mathrm{D}$. On the other hand, policy support also makes enterprise less risky, that is, reducing the likelihood of unsellable products by expanding demand.

As shown in Figure 4, when policy support efforts $\left(F_{P}\right)$ improve from $F_{P}$ to $F_{P}{ }^{\prime}$, in order to analyze the function of $\mathrm{F}_{\mathrm{P}}$, we take the control variable methods to control $\mathrm{F}, \mathrm{F}_{\mathrm{T}}$ and $\mathrm{F}_{\mathrm{R}}$, so that then the $\mathrm{F}_{\mathrm{I}}{ }^{\prime}$ record is obviously smaller than $\mathrm{F}_{\mathrm{I}}$. That is to say, the effort to conduct innovative research of green entrepreneurial enterprises under the influence of policy support is less than the effort when there is a lack of policy support or the policy support is weak. As such, policy support has brought impetus to the enterprise's green entrepreneurial activities. Therefore, this paper puts forward Proposition 2.

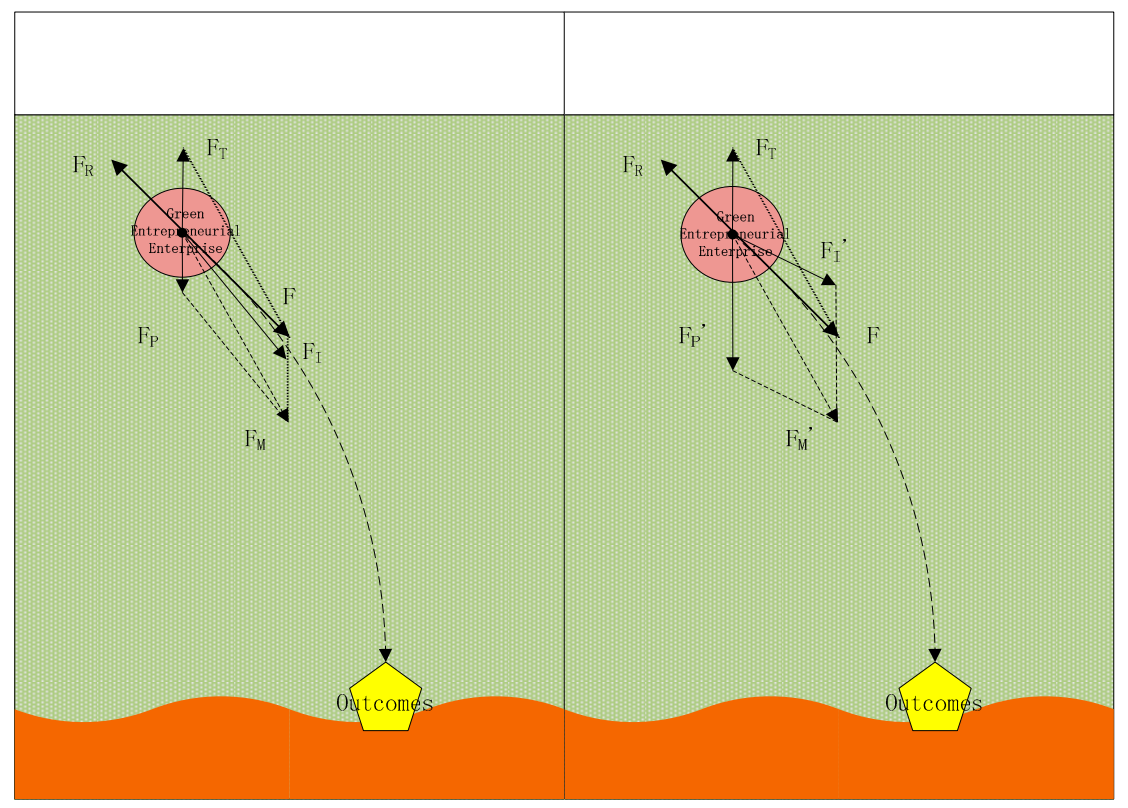

Figure 4. The promoting role of policy support.

Proposition 2. Policy support can give impetus to an enterprise's green entrepreneurship.

For green entrepreneurial enterprises, policy support alone will not be enough in completing innovative research and development of new products, services or technologies. There is also a need to ensure successful access to innovations through innovative research activities. According to the research of Sofka and Grimpe [13] and Köhler et al. [14], on the one hand, enterprises need to research the technical knowledge, skills, techniques, processes and other aspects required in the design, R\&D 
and production of new products or services, thus helping them overcome technological complexity. On the other hand, enterprises also need to research market knowledge in order to understand customer preferences, market demand and other conditions, so as to improve the design, development, production and other processes and to adjust the direction of design and R\&D and other activities within entrepreneurial process at any time. Therefore, enterprises are able to avoid wasting time and resources or even experiencing failure because of a deviation in their direction. In addition, green entrepreneurship requires a significant amount of investment in the innovation of products and services and these inputs put pressure on enterprises. Moreover, there is the continuous deepening of the process of green entrepreneurship and the continuous clear about the ultimate innovative outcomes that can be obtained, in order to reduce the burden caused by this pressure, the efforts by entrepreneurial enterprises into the market knowledge research will be appropriately shifted to technical knowledge research, allowing greater purpose and the ability to complete the "treasure hunt" process as soon as possible. As shown in Figure 5, the size of the innovative research represented by $F_{I}$ is constant and the direction is deflected downward to $F_{I}{ }^{\prime}$, that is, part of the input in market knowledge research in the horizontal direction is switched to the research of the technical knowledge in the vertical direction. Therefore, this paper puts forward Proposition 3.

Proposition 3. Innovative research by green entrepreneurial enterprise not only provides impetus for their entrepreneurial activities, but also serves to correct their trajectories.

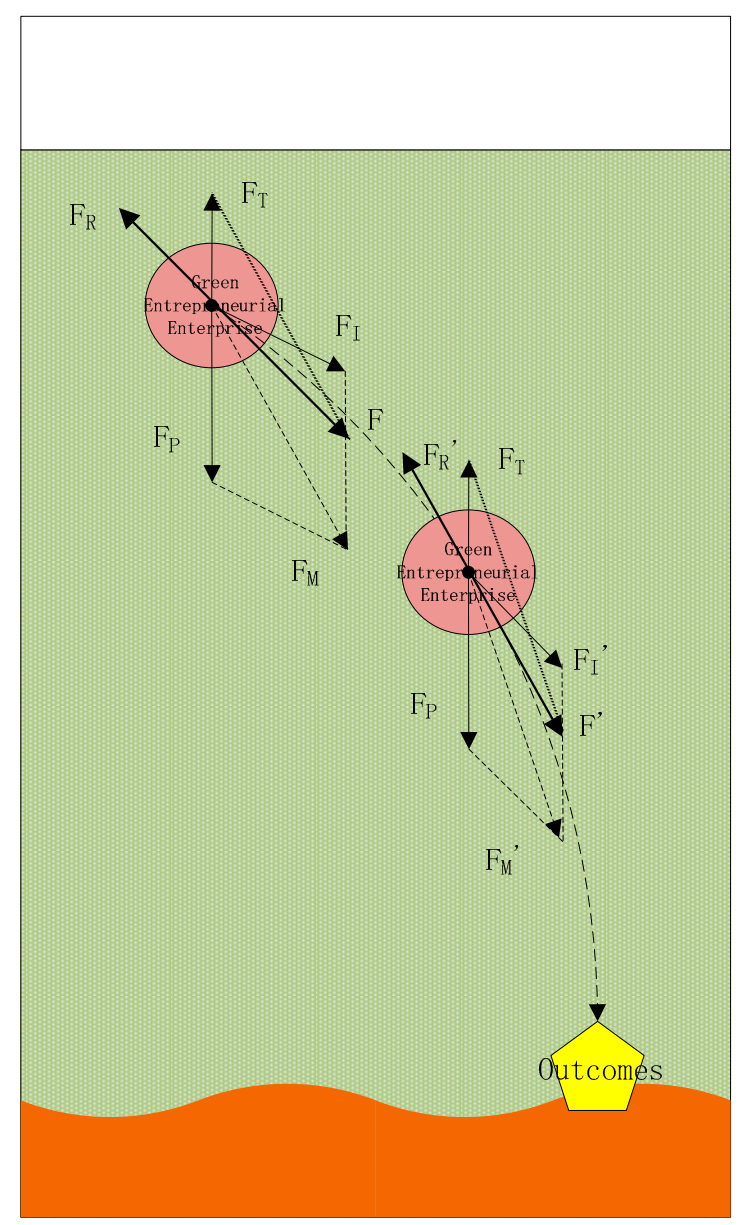

Figure 5. Entrepreneurial research changes with the development of green entrepreneurship. 


\section{Case Study}

\subsection{Methods and Sample}

Case studies examine the complexities of samples and help researchers to provide solid analyses [32]. A single case study approach helps us to capture and track new phenomena and emerging issues resulting from management practices, as well as providing a better view of issues raised within the research framework [33,34]. A detailed study of individual cases can provide deeper insights into the complexities of the enterprise and offer a more detailed presentation of their operational state [35]. At present, the selection of typical cases is common practice based on a study of case studies. As Eisenhardt points out, for the case study approach, random samples are not only unnecessary but generally not desirable [36]. Pettigrew even repeatedly emphasized that it is more appropriate to select a typical and extreme case to study [33]. The same holds true for Yin, who argues that case studies require sample selection to be either significant or extreme [32]. Therefore, this paper selects a typical case with which to study green entrepreneurship under the policy support in a transitional economy.

This paper follows common practice in the research of green entrepreneurship and selected enterprises in industries with green attributes during the sample selection [37]. Based on the research purpose of this article, it is necessary to conduct an in-depth analysis of how green enterprises reflect on policy support and any changes to their innovative research behavior during the process of green entrepreneurship. Therefore, we use a typical case study approach to analyze data obtained through a follow-up survey, in-depth interviews, and web-based collection.

In terms of sample selection, we select a Chinese company named Songyuan Guanghe Energy Co., Ltd. (Songyuan, China). (hereinafter referred to as "Guanghe Energy"). Guanghe Energy is a high-tech enterprise established in 2013, which has set up an area of 250,000 square meters in the Songyuan Petrochemical Park in Jilin Province. Its main business is the deep processing of agricultural wastes, such as straw, to produce biomass energy and biomass materials. Its products mainly include biomass energy like bio-butanol, bio-ethanol, and biomass gas and lignin materials. On the basis of in-depth cooperation with research institutes such as Chinese Academy of Sciences and Chinese Academy of Forestry, Guanghe Energy not only made developments in biomass energy, but also gained a deeper understanding of lignin materials. In 2017, it established Beijing Hemuzhijia Technology Development Co., Ltd. (Beijing, China). (hereinafter referred to as "Hemuzhijia"). At present, Hemuzhijia cooperates with large enterprises such as Craft Master to engage in building materials and decoration materials based on lignin, such as doors, windows, floors, interior and exterior wall panels, floors, furniture and biological polyurethanes. After many years of design, research and development and other innovative activities, the product series of Guanghe Energy and Hemuzhijia are basically complete, forming their own products and technology systems. Its core technology is supported by more than 20 patents, mainly involving the separation and directional conversion of three components of agricultural wastes such as straws, non-polluting gas explosions and the simultaneous fermentation of xylose and glucose to produce ethanol, butanol, acetone and bio-natural gas technologies. Some of the technologies have reached advanced levels by both international and domestic standards. At present, Guanghe Energy and Hemuzhijia have reached a stable production ability and are trying to carry out product industrialization.

The main reasons for choosing this company are as follows: firstly, the industry is typical. Guanghe Energy has engaged in the energy industry and the construction industry which are closely related to the daily needs of human beings. The green development of the energy industry and the construction industry is also a current concern in China and throughout the world. Thus, the green entrepreneurship of Guanghe Energy covers the business of these two industries, showing a certain degree of typicality. Secondly, most of the green entrepreneurial enterprises are innovative new ventures or small and medium-sized businesses (SMEs) that are able to respond more positively to the demand for green products than large ones in almost any market segment [2,22]. As a mid-sized 
enterprise that continuously undertakes green entrepreneurship, Guanghe Energy has entered the construction industry after undertaking green entrepreneurship in the energy industry. Studying it will help us to have a deeper understanding of why enterprises start green entrepreneurship and the process of green entrepreneurship. This is also of great significance to a large number of small and medium-sized enterprises that are interested in green entrepreneurship. Thirdly, Guanghe Energy owns a number of advanced technologies and its technological innovation places it in a leading position within the industry. Its industrialized production technologies of bio-ethanol and bio-butanol and the production technology of lignin building materials and decoration materials have reached an advanced level within China or even the world. Guanghe Energy has strong motivation and innovation in the research and development of green technologies while also undertaking the risks brought by the technical and market uncertainties in the process, showing a strong entrepreneurial orientation. Fourthly, the availability and reliability of research data is relatively high. The research team for this paper continued to track the green entrepreneurial process of Guanghe Energy from 2014 onwards, as well as conducting several investigations and in-depth exchanges with many senior executives of the enterprise. Therefore, we are familiar with the growth path, operation mode and other aspects of the enterprise, so the reliability and consistency of the information and data we obtain can be guaranteed. Finally, Guanghe Energy is a mid-sized enterprise engaging in green entrepreneurship, since its establishment, Guanghe Energy has been engaged in the research, development and production of green and clean energy and environmental protection materials. At present, its research and development achievements are in the transitional phase from a small-scale production process to incremental production. In other words, the company has just undergone the completion of the "treasure hunting" stage and reached the "treasure excavation" stage of "Green Ocean Treasure Hunting". Its development is most in line with the current entrepreneurial environment in China. Thus, compared with enterprises that have been engaged in green entrepreneurship for many years or have just started green entrepreneurship, Guanghe Energy is more suitable as a reference for those enterprises that are or will soon start green entrepreneurship. Therefore, this paper chooses Guanghe Energy as the research object to analyze the role policy support plays, in addition to the enterprises themselves, in product improvement, research and development, etc., in the process of green entrepreneurship. This paper believes Guanghe Energy to be proof of its earlier propositions.

\subsection{The Guiding Role of Policy Support}

China's policy support for renewable energy was relatively weak before 2005 . Since the promulgation of the Renewable Energy Law in 2005, policies on support and management of renewable energy have been promulgated one after another, and the policy support on renewable energy industry has also significantly increased. However, due to limitations resulting from technology development level and cost, the focus of policy support mainly lies in the fields of wind energy and solar energy utilization, which require relatively low cost and technical difficulty in the early stages. The support for renewable energy in other fields, such as biomass energy, was relatively weak, as shown by the "Renewable Energy Industry Development Guidance Catalog" issued by the National Development and Reform Commission(NDRC) in 2005, where more than half of projects, 58 out of a total of 88 projects, supported wind energy and solar energy projects. With the gradual improvement of technical skills, China has started to increase support for renewable energy in other fields such as biomass energy. For example, the "Medium and Long-term Development Plan for Renewable Energy" formulated by the NDRC in 2007 emphasizes that the technology to use non-grain raw materials to produce fuel ethanol has met preliminary commercial development conditions. The "12th Five-Year Plan for Biomass Energy Development" compiled by the National Energy Administration of China in 2012 focuses on the field of biomass energy, and emphasizes the development of non-grain biological liquid fuels as a key task, establishing a corresponding bio-ethanol and other cellulosic bio-fuels industrialization demonstration project. As China's support for biomass energy is gets increasingly stronger, the attractiveness of this field is gradually increasing. Mr. S, the founder of Guanghe 
Energy, who has been engaged in the production and sales of grain alcohol and possesses an in-depth understanding of the liquid fuel industry, has a strong interest in this field after noticing that China encouraged the production of biomass energy products. Therefore, since it was established Guanghe Energy has aimed at this field and hopes to take a place in this area.

As a large agricultural country, China produces a large amount of agricultural waste every year. In order to make full use of this waste and reduce pollution, China has promulgated many policies. For example, the "Opinions on Accelerating the Comprehensive Utilization of Crop Straw", which the State Council General Office issued in 2008, emphasizes the prohibition of open burning crop straw and strengthening the comprehensive utilization of straw. In his experience in the liquid fuel industry, Mr. S learned that there are a large number of crop straws in China, and that these straws are often incinerated without utilization, resulting in huge waste and pollution. Since straw is rich in cellulose, which has the potential to be used as a raw material in biomass liquid fuel production, the only thing missing is the industrial production technology to make use of this straw in the manufacture of biomass fuels. After studying relevant policies, Mr. S believes that policy support of biomass energy is gradually increasing, and its future market is worth to looking forward to. There are sufficient low-cost sources of agricultural waste in China and since the industrialized production of bio-ethanol and bio-butanol from this agricultural waste is technically possible to achieve, Mr. S decided to create Guanghe Energy and engage in business in this area.

With the development of Guanghe Energy's R\&D activities to produce biomass fuels from straw, the lignin produced during this process is found to be an excellent material with strong stability and anti-aging properties. Increasingly serious concerns about the current damage caused by indoor air pollution have led to China's regulations on the quality of building decoration materials to address the hazards of formaldehyde and other decoration pollution like "Indoor Air Quality Standards". Guanghe Energy began to consider the use of lignin due to its excellent characteristics suitable for building decoration materials, and after repeated research and testing found that lignin materials have many excellent features, such as being flame retardant, waterproof, non-deforming, anti-aging, formaldehyde-free and having high pressure resistance, which is difficult to achieve with general wood. In recent years, China has introduced a series of policies to encourage prefabricated building to deal with the problem of inefficient use of resources in the construction industry, for instance prefabricated buildings are planned to account for 50\% of new buildings until 2025 in the "Construction Industry Modernization Development Program" promulgated in 2015 by the Ministry of Housing and Urban-Rural Development. In 2016, the "Guiding Opinions on Vigorously Developing Prefabricated Buildings" promulgated by the State Council opened the door to Guanghe Energy for its application of lignin materials. In order to maximize the advantages of lignin materials, Guanghe Energy invested to set up Hemuzhijia to specialize in the production and application of lignin materials and to make corresponding innovations in response to the promising prospect of the prefabricated buildings promoted by China. Their intention is to further perfect and industrialize the use of lignin materials to produce building decorating materials and encourage the use of these new eco-friendly materials in the process of prefabricated building and decoration.

From the process by which Guanghe Energy was created and chose to enter into the biomass energy industry, invest in the establishment of Hemuzhijia and enter into the construction industry, we can see that a guiding role was played by policy support. The attraction brought by the corresponding policies promulgated by the government encouraged them to enter these two industries and make unremitting efforts.

\subsection{The Driving Effect of Policy Support}

In its green entrepreneurship, Guanghe Energy constantly carries out product innovation, research and development. In addition to its continuous input in this process, policy support also provides impetus to it. For example, the "Renewable Energy Law" stipulates that in addition to encouraging enterprises to produce biological liquid fuels, the state also requires oil sales companies to include 
biological liquid fuels into their sales systems (such as ethanol gasoline). Biological liquid fuels also belong to the project of developing special fund support projects and allowing financial institutions to provide preferential loans with financially discounted interest. As well as regulations like the "Opinions on Accelerating the Comprehensive Utilization of Crop Straw" issued by the General Office of the State Council, the "Circular on Further Accelerating the Comprehensive Utilization of Crop Straw and Prohibition of Burning" promulgated by NDRC and other departments stipulates to prohibit the burning of straw and implement preferential tax policies to encourage its comprehensive utilization. These policies also subsidize the R\&D of straw fuel ethanol production technology and equipment and encourage financial banking institutions to provide credit support and other policies for the enterprises to carry out straw storage, processing and utilization. In its R\&D, purchase of equipment, procurement of materials and trial production, Guanghe Energy has invested a lot of resources, although policy support such as subsidies, tax incentives, credit support, and lending incentives has lessened the pressure on the company. Taking the cellulosic ethanol production business of Guanghe Energy as an example, since 2012 the government's policy support of grain-based fuel ethanol has been gradually phased out, while subsidies for non-grain ethanol produced from raw materials such as cassava and cellulose have been relatively stable. Guanghe Energy, which started its cellulosic ethanol production line in 2014, also received some policy support during the production and sales of these products. On the one hand, the government's promotion of fuel ethanol and the reduction of support for grain-based fuel ethanol has opened up more market space for cellulosic ethanol. On the other hand, the subsidy policy has also been effective in reducing the cost of its products. The production data of Guanghe Energy shows that the cost of producing cellulosic ethanol per ton is about $7600 \mathrm{CNY}$, of which, 6 tons of raw materials (agricultural waste) costs about $3600 \mathrm{CNY}$ and the processing cost is about $4000 \mathrm{CNY}$. The price of cellulosic ethanol entering China's automobile fuel ethanol system is about $8300 \mathrm{CNY}$ per ton. At the same time, Guanghe Energy can produce 2 tons of by-product lignin thermoplastic materials (5000 CNY per ton) and 500 cubic meters of CNG (about $1750 \mathrm{CNY}$ in total). Accordingly, the benefits are very substantial.

Since 2015, prefabricated building related policies have been intensively promulgated. For example, in 2015, the "Construction Industry Modernization Development Program" promulgated by the Ministry of Housing and Urban-Rural Development planned to make prefabricated buildings account for more than $20 \%$ of new buildings by 2020 , reaching $50 \%$ by 2025 . The "Industrial building evaluation standards" at the end of the same year also opted to comprehensively promote prefabricated buildings nationwide starting in 2016. The "Guiding Opinions on Vigorously Developing Prefabricated Buildings" promulgated by the General Office of the State Council in 2016 also required the development of prefabricated concrete structures, steel structures and modern wood structure buildings. These policies all emphasize that increasing the development of prefabricated buildings, thus expands the market for prefabricated buildings domestically and increases the demand for prefabricated buildings and related green building materials and prefabricated decoration. This demand also became the driving force that prompted Guanghe Energy to set up Hemuzhijia and enter into the construction industry. The "Guiding Opinions on Vigorously Developing Assembled Buildings" provides subsidisation policies and tax rebate policies on eligible prefabricated building related products and encourages local governments to implement support in planning, land supply, financial and other aspects. Moreover, there is additional direct policy support that can help Hemuzhijia's green entrepreneurship relating to prefabricated buildings. The construction materials and furniture provided by Hemuzhijia is made by processing the lignin obtained from the biological refining of straw. Chinese policies promoting the comprehensive utilization of crop straw also provide tax support and credit support for this process. This direct policy support directly relieves the pressure on Hemuzhijia's resources for product research and development, trial production and other processes so that it can smoothly complete the research and development, production and construction of a wide range of environmental-friendly building and decoration materials. At present, Hemuzhijia has 
successfully used these environmental-friendly materials to build a building-decoration integrated sample of a prefabricated house.

We analyzed the process by which Guanghe Energy entered into the biomass energy industry to $R \& D$, produce and sell cellulosic liquid fuels and of Hemuzhijia using lignin to research and produce building materials and entering into the field of prefabricated buildings. We found that national and local policies play a supportive role and it is this policy support that has helped to boost Guanghe Energy's development and reduce pressure from resource constraints and technological complexity.

\subsection{Innovative Research in Green Entrepreneurship}

Guanghe Energy's green entrepreneurship process was carried out after identifying potential opportunities to make biomass energy products from agricultural waste. It also constantly conducted innovative research during product development. On the one hand, there were many kinds of agricultural waste that could be used by Guanghe Energy (such as straw, weeds, fruit shells etc.) and there were also many potential products (such as fuel ethanol and bio-diesel). In addition to the technical possibilities, the question of which kind of raw materials to use to eventually produce the product requires market knowledge research. After broad market knowledge research, wasted straws, which caused serious pollution, and fuel ethanol, which was promoted by the government, became Guanghe Energy's main goal. On the other hand, as the market knowledge research continued, technical knowledge research also allowed Guanghe Energy to deepen its understanding of related knowledge. Their targeted innovation achievements gradually became locked on cellulose ethanol, bio-gas and lignin and other products produced by further processing agricultural waste, such as straw. At this time, in order to relieve the pressure caused by resource consumption in the process of product innovation and R\&D, Guanghe Energy paid more attention to overcoming the technological complexity that hindered the industrial production of products such as cellulosic ethanol by straw. This process required repeated exploration in order achieve the desired results. In the process, the leading team, management personnel and technicians of Guanghe Energy continued to work day and night and minimized other expenses to focus on innovation, eventually realizing the technology to convert agricultural waste to cellulose ethanol on an industrial scale in 2014. In the scientific and technological appraisal done by the Chinese Academy of Sciences and the Department of Industry and Information of Jilin Province, this technology has been identified as at an advanced level internationally.

The same applies to the R\&D and utilization of lignin materials and the company's entry into the field of prefabricated buildings. While researching market knowledge, Guanghe Energy identified the opportunity brought by its lignin products in the production of environmental-friendly building materials, as well as China's efforts to promote prefabricated buildings, leading them to invest establish Hemuzhijia, which specializes in this business. During this process, Hemuzhijia understood consumer preferences and market needs through constant market knowledge research, and adjusted and improved the performance of its lignin materials and the design and construction of its prefabricated buildings through technical knowledge research. Therefore, they produced building materials and furniture with better performance and better application of lignin materials in the prefabricated buildings and prefabricated decoration, managing to realize a near perfect integration of materials, construction and decoration.

We analyzed the process of developing and producing biomass energy products from agricultural waste by Guanghe Energy and the process of developing and manufacturing building materials and innovative prefabricated building technology with the use of lignin by Hemuzhijia. Through this analysis it can be found that innovative research plays an essential role in green entrepreneurship. One the one hand, technical knowledge research helps it to overcome technological complexity. On the other hand, market knowledge research helps it to determine its own development direction more accurately and move its green entrepreneurial activity forward towards its targeted innovative achievements. 


\section{Conclusions and Outlook}

This paper studies green entrepreneurial activities under the guidance of policy support in the transitional economy, and gives a more in-depth understanding of green entrepreneurship by making the process analogous to process of conducting a "treasure hunt in the sea". On this basis, we construct the "Green Ocean Treasure Hunting" model and regard the factors that affect the development of green entrepreneurial enterprises, such as government support, innovative research and technological complexity, as the forces acting on enterprises. We use this mechanics model to analyze the influences that the enterprise will face in its pursuit of innovation achievement during the process of green entrepreneurship. Based on the analysis process, several propositions are proposed, and the case of a high-tech enterprise in China is selected as a proof of these propositions. This paper constructs and analyzes the theory of the "Green Ocean Treasure Hunting" model, which draws on physics principles that can make the process of green entrepreneurship more visible and easier to understand. In practice, the research in this paper may be a reference for individuals and organizations that are willing to conduct green entrepreneurship. It propounds that they should give full consideration to the motivation and resistance of green entrepreneurship before making decisions. As for those enterprises that are already undertaking green entrepreneurship, they should make full use of policy support and innovative research so as to reduce the negative impact caused taking a wrong direction.

The research in this paper draws on the principles of physics, but for the impact of various forces that affect the green entrepreneurial enterprises, we mainly did qualitative analysis. Future research could conduct quantitative research based on more primary and secondary data, so as to better reflect the role of the mechanical model. In addition, this paper mainly studies the green entrepreneurship process under the guidance of policy support. In order to make the research process clearer, it ignores the influence of other factors in the process of building and analyzing models. Future research could also consider the role of culture, enterprise structure and other internal and external factors on green entrepreneurial enterprises.

Acknowledgments: This work was financially supported by the China Natural Science Foundation (71472071, 71602016), and Science Foundation of Ministry of Education of China (16YJC630025), Liaoning S\&T Project (2017050262), Liaoning E\&S development project (20181slktqn-014), Provincial Nature Science Foundation of Guangdong (Nos. 2015A030310271 and 2015A030313679), Zhongshan City Science and Technology Bureau Project (No. 2017B1015).

Author Contributions: Writing: Baoshan Ge, Fan Sheng and Yang Gao; Providing case and idea: Sang-Bing Tsai and Xiaomin Du; Providing revised advice: Yang Gao and Sang-Bing Tsai.

Conflicts of Interest: The authors declare no conflicts of interest.

\section{References}

1. Marra, A.; Antonelli, P.; Dell'Anna, L.; Pozzi, C. A network analysis using metadata to investigate innovation in clean-tech-Implications for energy policy. Energy Policy 2015, 86, 17-26. [CrossRef]

2. Marra, A.; Antonelli, P.; Pozzi, C. Emerging green-tech specializations and clusters-A network analysis on technological innovation at the metropolitan level. Renew. Sustain. Energy Rev. 2017, 67, 1037-1046. [CrossRef]

3. Dean, T.J.; Mcmullen, J.S. Toward a theory of sustainable entrepreneurship: Reducing environmental degradation through entrepreneurial action. J. Bus. Ventur. 2007, 22, 50-76. [CrossRef]

4. Kai, H.; Wüstenhagen, R. Greening Goliaths versus emerging Davids-Theorizing about the role of incumbents and new entrants in sustainable entrepreneurship. J. Bus. Ventur. 2010, 25, 481-492.

5. Shepherd, D.A.; Patzelt, H. The New Field of Sustainable Entrepreneurship: Studying Entrepreneurial Action Linking "What Is to Be Sustained" With "What Is to Be Developed". Entrep. Theory Pract. 2011, 35, 137-163. [CrossRef]

6. Kate, K.; Eva, C. Making Sense of Ecopreneurs' Decisions to Sell Up. Bus. Strategy Environ. 2012, 21, 71-85.

7. Silajdžić, I.; Kurtagić, S.M.; Vučijak, B. Green entrepreneurship in transition economies: A case study of Bosnia and Herzegovina. J. Clean. Prod. 2015, 88, 376-384. 
8. Corbett, J.; Montgomery, W. Environmental entrepreneurship and interorganizational arrangements: A model of social-benefit market creation. Strateg. Entrep. J. 2017, 11, 422-440. [CrossRef]

9. Fonseca, R.; Lopez-Garcia, P.; Pissarides, C.A. Entrepreneurship, entrepreneurial enterprise costs and employment. Eur. Econ. Rev. 2001, 45, 692-705. [CrossRef]

10. Ge, B.S.; Jiang, D.K.; Gao, Y.; Tsai, S.B. The influence of legitimacy on a proactive green orientation and green performance: A study based on transitional economy scenarios in china. Sustainability 2016, 8, 1344. [CrossRef]

11. Pinkse, J.; Groot, K. Sustainable entrepreneurship and corporate political activity: Overcoming market barriers in the clean energy sector. Entrep. Theory Pract. 2015, 39, 633-654. [CrossRef]

12. Katila, R.; Ahuja, G. Something old, something new: A longitudinal study of search behavior and new product introduction. Acad. Manag. J. 2002, 45, 1183-1194. [CrossRef]

13. Sofka, W.; Grimpe, C. Specialized search and innovation performance-Evidence across Europe. R D Manag. 2010, 40, 310-323. [CrossRef]

14. Köhler, C.; Sofka, W.; Grimpe, C. Selective search, sectoral patterns, and the impact on product innovation performance. Res. Policy 2012, 41, 1344-1356. [CrossRef]

15. Kim, W.C.; Mauborgne, R. Blue Ocean. Strategy; Harvard Business School Press: Boston, MA, USA, 2005.

16. Cappa, F.; Sette, F.D.; Hayes, D.; Rosso, F. How to deliver open sustainable innovation: An integrated approach for a sustainable marketable product. Sustainability 2016, 8, 1341. [CrossRef]

17. Rodriguez, M.A.; Ricart, J.E.; Sanchez, P. Sustainable development and the sustainability of competitive advantage: A dynamic and sustainable view of the firm. Creativity Innov. Manag. 2002, 11, 135-146. [CrossRef]

18. Schaltegger, S.; Wagner, M. Sustainable entrepreneurship and sustainability innovation: Categories and interactions. Bus. Strategy Environ. 2011, 20, 222-237. [CrossRef]

19. Block, F. Swimming against the current: The rise of a hidden developmental state in the United States. Politics Soc. 2008, 36, 169-206. [CrossRef]

20. Baldwin, C.Y.; Clark, K.B. Design Rules: The Power of Modularity; MIT Press: Cambridge, MA, USA, 2000.

21. Fleming, L.; Sorenson, O. Technology as a complex adaptive system: Evidence from patent data. Res. Policy 2001, 30, 1019-1039. [CrossRef]

22. Ndubisi, N.O.; Nair, S.R. Green entrepreneurship (GE) and Green Value Added (GVA): A conceptual framework. Int. J. Entrep. 2009, 13, 21-34.

23. Lewis, J.I.; Wiser, R.H. Fostering a renewable energy technology industry: An international comparison of wind industry policy support mechanisms. Energy Policy 2007, 35, 1844-1857. [CrossRef]

24. Stigson, P.; Dotzauer, E.; Yan, J. Improving policy making through government-industry policy learning: The case of a novel Swedish policy framework. Appl. Energy 2009, 86, 399-406. [CrossRef]

25. Cohen, B.; Winn, M.I. Market imperfections, opportunity and sustainable entrepreneurship. J. Bus. Ventur. 2007, 22, 29-49. [CrossRef]

26. Shane, S.; Venkataraman, S. The promise of entrepreneurship as a field of research. Acad. Manag. Rev. 2000, 25, 217-226. [CrossRef]

27. Mcwilliams, A.; Siegel, D. Corporate social responsibility: A theory of the firm perspective. Acad. Manag. Rev. 2001, 26, 117-127.

28. Tencent Finance. Jusfoun Bigdata. Big Data Interpretation of the New Energy Industry: The Top 10 Occupy 70\% Market. Available online: http:/ finance.qq.com/original/bigdata/xinnengyuan.html (accessed on 3 December 2017).

29. Busenitz, L.W.; Gómez, C.; Spencer, J.W. Country Institutional Profiles: Unlocking Entrepreneurial Phenomena. Acad. Manag. J. 2000, 43, 994-1003. [CrossRef]

30. Porter, M.E.; Claas, V.D.L. Toward a New Conception of the Environment-Competitiveness Relationship. J. Econ. Perspect. 1995, 9, 97-118. [CrossRef]

31. Ramanathan, R.; He, Q.; Black, A.; Ghobadian, A.; Gallear, D. Environmental regulations, innovation and firm performance: A revisit of the Porter hypothesis. J. Clean. Prod. 2017, 155, 79-92. [CrossRef]

32. Yin, R.K. Case Study Research Design and Methods; SAGE Publications Inc.: Thousand Oaks, CA, USA, 2013.

33. Pettigrew, A.M. Longitudinal field research on change: Theory and practice. Organ. Sci. 1990, 1, $267-292$. [CrossRef]

34. Siggelkow, N. Persuasion with case studies. Acad. Manag. J. 2007, 50, 20-24. [CrossRef] 
35. Dyer, W.G.; Wilkins, A.L. Better Stories, not better constructs, to generate better theory: A rejoinder to Eisenhardt. Acad. Manag. Rev. 1991, 16, 613-619.

36. Eisenhardt, K.M. Building theories from case study research. Acad. Manag. Rev. 1989, 14, 532-550.

37. OECD. OECD Entrepreneurship at a Glance 2011. Available online: http://www.oecd-ilibrary. org $/$ docserver $/$ download $/ 3011021$ e.pdf? expires $=1517390284 \&$ id=id\&accname $=$ guest\&checksum $=$ E15844D9C63CC62C99688EBE360BC2DF (accessed on 5 November 2017). 